\title{
Co-doping Characteristics of $\mathrm{Si}$ and $\mathrm{Zn}$ with $\mathrm{Mg}$ in P-type GaN
}

K.S. Kim, C.S. Oh, M.S. Han, C.S. Kim, G.M. Yang*, J.W. Yang, C.-H. Hong, C.J. Youn, K.Y. Lim, and H.J. Lee

Department of Semiconductor Science \& Technology and Semiconductor Physics Research Center, Chonbuk National University, Chonju 561-756, Korea

*Author to whom correspondence should be addressed gyemo@ moak.chonbuk.ac.kr

\begin{abstract}
We investigated the doping characteristics of $\mathrm{Mg}$ doped, $\mathrm{Mg}$-Si co-doped, and $\mathrm{Mg}-\mathrm{Zn}$ codoped GaN films grown by metalorganic chemical vapor deposition. We have grown pGaN film with a resistivity of $1.26 \Omega \mathrm{cm}$ and a hole density of $4.3 \times 10^{17} \mathrm{~cm}^{-3}$ by means of $\mathrm{Mg}$-Si co-doping technique. The $\mathrm{Mg}$-Si co-doping characteristic was also explained effectively by taking advantage of the concept of competitive adsorption between $\mathrm{Mg}$ and $\mathrm{Si}$ during the growth. For $\mathrm{Mg}-\mathrm{Zn}$ co-doping, $\mathrm{p}-\mathrm{GaN}$ showing a low electrical resistivity $(0.7 \Omega \mathrm{cm})$ and a high hole concentration $\left(8.5 \times 10^{17} \mathrm{~cm}^{-3}\right)$ was successfully grown without the degradation of structural quality of the film. Besides, the measured specific contact resistance for $\mathrm{Mg}-\mathrm{Zn}$ co-doped $\mathrm{GaN}$ film is $5.0 \times 10^{-4} \Omega \mathrm{cm}^{2}$, which is lower value by one order of magnitude than that for only $\mathrm{Mg}$ doped $\mathrm{GaN}$ film $\left(1.9 \times 10^{-}\right.$ $\left.{ }^{3} \Omega \mathrm{cm}^{2}\right)$.
\end{abstract}

\section{INTRODUCTION}

The realization of high conducting p-type $\mathrm{GaN}$ film is one of the key factors to the success of GaN based light emitting devices such as light emitting diodes (LEDs) and laser diodes with low series resistance and high external quantum efficiency. $\mathrm{Mg}$ has been used as a typical acceptor dopant in $\mathrm{GaN}$ grown by metalorganic chemical vapor deposition (MOCVD), known to have the smallest ionization energy compared with other acceptor dopant sources. Nevertheless, it is difficult to get the p-type GaN with low resistivity and high hole concentration because it is still deep from valence band maximum. Recently, it was theoretically suggested that co-doping of n-type dopants (eg. $\mathrm{Si}, \mathrm{O}$, etc.) together with p-type dopants (eg. $\mathrm{Mg}, \mathrm{Be}$, etc.) in $\mathrm{GaN}$ is effective for the fabrication of high-conductivity p-type GaN[1, 2]. It drives us to the study of co-doping characteristics in p-type GaN.

In this work, we have studied the co-doping characteristics of $\mathrm{Si}$ with $\mathrm{Mg}$ as well as $\mathrm{Zn}$ with Mg.

\section{EXPERIMENTS}

All samples were prepared in a horizontal MOCVD reactor. The source materials of $\mathrm{Ga}, \mathrm{N}, \mathrm{Mg}, \mathrm{Si}$, and $\mathrm{Zn}$ are trimethylgallium (TMGa), ammonia $\left(\mathrm{NH}_{3}\right)$, biscyclopentadienylmagnesium $\left(\mathrm{Cp}_{2} \mathrm{Mg}\right), 100 \mathrm{ppm}$ monosilane $\left(\mathrm{SiH}_{4}\right)$, and diethylzinc (DEZn), respectively. $\mathrm{Mg}$ doped, $\mathrm{Mg}-\mathrm{Si}$, and $\mathrm{Mg}-\mathrm{Zn}$ codoped $\mathrm{GaN}$ overlayers with thicknesses of $1-2$ microns were grown in $\mathrm{H}_{2}$ ambient at $1080{ }^{\circ} \mathrm{C}$ with various flow rates of $\mathrm{Cp}_{2} \mathrm{Mg}, \mathrm{SiH}_{4}$, and DEZn. Other growth conditions are the same with those of the unintentionally doped GaN[3]. 


\section{RESULTS AND DISCUSSION}

\section{Mg doped GaN}

In order to investigate $\mathrm{Mg}$ doping characteristics in $\mathrm{GaN}$, several kinds of $\mathrm{GaN}$ films with different hole concentrations obtained by varying the amount of $\mathrm{Cp}_{2} \mathrm{Mg}$ flow rate were grown. Figure 1 shows typical Hall characteristics of the $\mathrm{GaN}$ films as a function of gas phase $[\mathrm{Mg}] /[\mathrm{Ga}]$ ratio measured at room temperature after post-growth rapid thermal annealing (RTA) in $\mathrm{N}_{2}$ ambient for $30 \mathrm{~s}$ at $900{ }^{\circ} \mathrm{C}$. Electrical characteristics were evaluated using the conventional van der Pauw Hall measurement in which magnetic field of 0.5 Tesla and currents between 10 and $100 \mathrm{uA}$ are applied. The GaN grown under a $[\mathrm{Mg}] /[\mathrm{Ga}]$ ratio of $5.4 \times 10^{-3}$ gives a high resistivity of $5.6 \Omega \mathrm{cm}$ and a low hole concentration of $7.3 \times 10^{16} \mathrm{~cm}^{-3}$. When the $[\mathrm{Mg}] /[\mathrm{Ga}]$ ratio is reached to 7.6 $\times 10^{-3}$, the hole concentration and resistivity abruptly change and have the maximum value of $6.7 \times 10^{17} \mathrm{~cm}^{-3}$ and the minimum value of $0.8 \Omega \mathrm{cm}$, respectively. If the $[\mathrm{Mg}] /[\mathrm{Ga}]$ ratio is larger than $7.6 \times 10^{-3}$, the hole concentration is gradually decreased and the resestivity is increased.

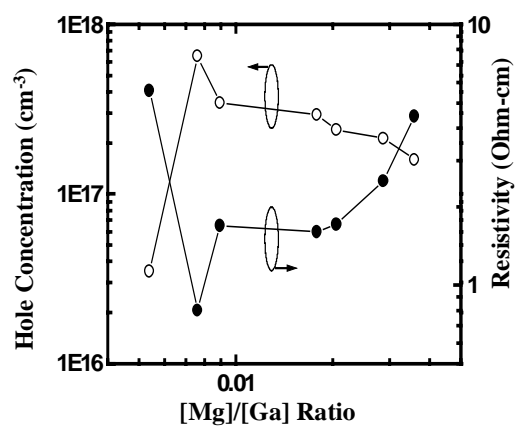

Figure 1, Dependence of resistivity (solid circle) and hole concentration (open circle) at room temperature on the gas phase $[\mathrm{Mg}] /[\mathrm{Ga}]$ ratio during the growth of GaN.

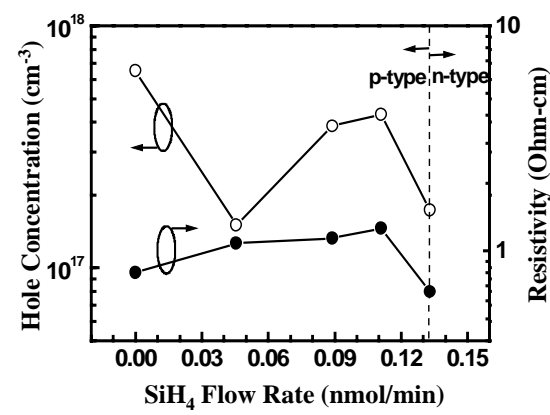

Figure 2, The resistivities (solid circles) and hole concentrations (open circles) as a function of $\mathrm{SiH}_{4}$ flow rate during the growth under the constant $[\mathrm{Mg}] /[\mathrm{Ga}]$ ratio of $7.6 \times 10^{-3}$.

\section{Mg-Si co-doped GaN}

For the purpose of studying Si co-doping characteristics in $\mathrm{Mg}$ doped $\mathrm{GaN}$ films, some kinds of specimens with different $\mathrm{SiH}_{4}$ flow rates were grown where the $[\mathrm{Mg}] /[\mathrm{Ga}]$ ratio was kept constant to $7.6 \times 10^{-3}$ thought to be the optimum condition. The Hall characteristics of the samples as a function of $\mathrm{SiH}_{4}$ flow rate are exhibited in Fig. 2, which are carried out after the identical RTA treatment as mentioned earlier. The Si and $\mathrm{Mg}$ co-doped p-type GaN layers show anomalous electrical behaviors. If considering only absolute net acceptor and donor concentrations, one can easily predict that hole 
concentrations are gradually decreased with increasing $\mathrm{SiH}_{4}$ flow rate, and finally type conversion arises. However, actual experimental data do not follow our expectation. In other words, the hole concentrations are increased as $\mathrm{SiH}_{4}$ flow rates increase before occurring type conversion. It is also interesting fact that type conversion occurs at a $\mathrm{SiH}_{4}$ flow rate of $0.13 \mathrm{nmol} / \mathrm{min}$, because this value is the quantity corresponding to the doping level of $1 \times 10^{17} \mathrm{~cm}^{-3}$ when applied in an undoped GaN. In addition, the maximum hole concentration $\left(4.5 \times 10^{17} \mathrm{~cm}^{-3}\right)$ of $\mathrm{p}-\mathrm{GaN}$ co-doped with $\mathrm{Si}$ and $\mathrm{Mg}$ shows the lower value compared to that $\left(6.7 \times 10^{17} \mathrm{~cm}^{-3}\right)$ of only $\mathrm{Mg}$ doped GaN. This abnormal behavior could be figured out by introducing the concept of competitive adsorption between $\mathrm{Mg}$ and $\mathrm{Si}$ atoms because they get into the same Ga sublattice site, though the quantity of $\mathrm{Si}$ atom is much less than that of $\mathrm{Mg}$ atoms in gas phase. Actually, if we compare the bond length of $\mathrm{Si}-\mathrm{N}$ and $\mathrm{Mg}-\mathrm{N}$, the bond length of $\mathrm{Mg}-\mathrm{N}(0.1439 \mathrm{~nm})$ is shorter than that of $\mathrm{Si}-\mathrm{N}(0.1572 \mathrm{~nm})$ [4]. Since the formation energy of $\mathrm{Si}-\mathrm{N}$ bonding is smaller than that of $\mathrm{Mg}-\mathrm{N}$, the occupation by $\mathrm{Si}$ atom into Ga sublattice site is easier than that by $\mathrm{Mg}$ atom. Accordingly, for $\mathrm{Mg}$ and $\mathrm{Si}$ co-doped $\mathrm{GaN}$ films, we presume that somewhat larger amount of $\mathrm{Si}$ atoms and smaller amount of $\mathrm{Mg}$ atoms are introduced into the co-doped $\mathrm{GaN}$ film than those independently calibrated. Besides, for $\left[\mathrm{SiH}_{4}\right]<0.13$ $\mathrm{nmol} / \mathrm{min}$, it is reasonable that the hole concentration is increased with increasing $\mathrm{SiH}_{4}$ flow rate because the increase of $\mathrm{Si}$ donors prevents from generating native defects leading to the self-compensation[1]. Therefore, this assumption can explain the experimental Hall data successfully and be proven by low temperature $(100 \mathrm{~K})$ measured PL spectra shown in Fig. 3.

Low temperature $(100 \mathrm{~K})$ photoluminescence (PL) spectra of GaN epilayers with different $[\mathrm{Mg}] /[\mathrm{Ga}]$ ratios are shown in Fig. 3 (a). The peaks at $3.25 \mathrm{eV}$ and $2.77 \mathrm{eV}$ are attributed to donor-acceptor pair (DAP)[5] and deep donor-acceptor-pair[6] transitions, respectively. However, at present status, we can not explain the exact origins of transition lines peaking at $3.17 \mathrm{eV}$ and $3.01 \mathrm{eV}$. It is apparent that blue emissions
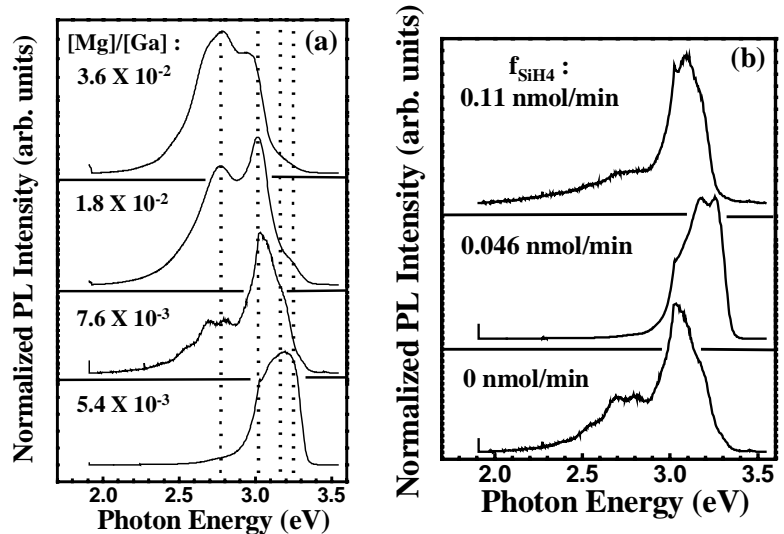

Figure 3, Low temperature (100 K) measured PL spectra of (a) $\mathrm{Mg}$ doped GaN films with various $[\mathrm{Mg}] /[\mathrm{Ga}]$ ratios, and (b) $\mathrm{Mg}$ $\mathrm{Si}$ co-doped GaN films with different $\mathrm{SiH}_{4}$ flow rates when keeping the $[\mathrm{Mg}] /[\mathrm{Ga}]$ ratio constant to $7.6 \times 10^{-3}$. 
around $2.77 \mathrm{eV}$ are increased and DAP transitions about $3.2 \mathrm{eV}$ are quenched as $[\mathrm{Mg}] /[\mathrm{Ga}]$ ratio increases. This means that the transition probability from the deep donor state to acceptor level is more probable and intense than that from the shallow donor state because the amount of deep donor is increased as $\mathrm{Mg}$ incorporation increases. This result shows good agreement with the electrical characteristics shown in Fig. 1.

The PL spectrum of Si and Mg co-doped GaN film with the $\mathrm{SiH}_{4}$ flow rate of $0.046 \mathrm{nmol} / \mathrm{min}$ in Fig. 3 (b) is similar to the result of the PL spectrum of $\mathrm{Mg}$ doped GaN layer with the $[\mathrm{Mg}] /[\mathrm{Ga}]$ ratio of $5.4 \times 10^{-3}$ as shown in Fig. 3 (a). It means that the introducing $\mathrm{SiH}_{4}$ source reduces the incorporation of $\mathrm{Mg}$ atoms, as we suppose.

\section{Mg-Zn co-doped GaN}

As we change $\mathrm{Cp}_{2} \mathrm{Mg}$ (under constant DEZn flow rate of $0.616 \mathrm{nmol} / \mathrm{min}$ ) and
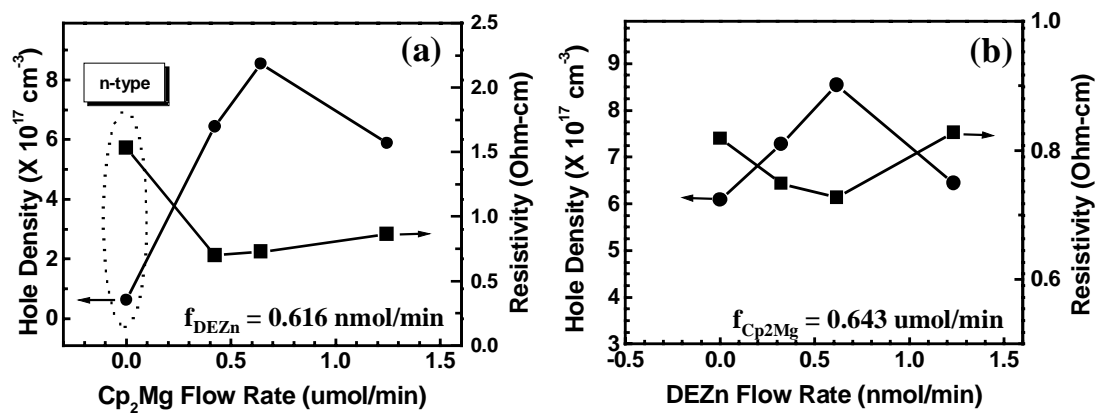

Figure 4, Dependence of hole densities and resistivities for the Mg-Zn co-doped GaN films at the condition of (a) various $C p_{2} M g$ flow rate and constant DEZn flow rate of $0.616 \mathrm{nmol} / \mathrm{min}$, and (b) various DEZn flow rate and a constant $\mathrm{Cp}_{2} \mathrm{Mg}$ flow rate of $0.643 \mathrm{umol} / \mathrm{min}$.

DEZn (under constant $\mathrm{Cp}_{2} \mathrm{Mg}$ flow rate of $0.643 \mathrm{umol} / \mathrm{min}$ ) flow rates, the variations of hole densities and resistivities of $\mathrm{Mg}-\mathrm{Zn}$ co-doped $\mathrm{GaN}$ films at room temperature are shown in Fig. 4 (a) and (b), respectively. Theoretically, the co-doping of two different ptype dopants in $\mathrm{GaN}$ is not helpful to achieve a high conducting p-type $\mathrm{GaN}$, because it forms a lot of native defect levels leading to hole compensation. However, in our prepared samples, we observed there exist optimum $\mathrm{Cp}_{2} \mathrm{Mg}$ flow rate of $0.643 \mathrm{umol} / \mathrm{min}$ and DEZn flow rate of $0.616 \mathrm{nmol} / \mathrm{min}$ showing higher hole concentration $\left(8.5 \times 10^{17}\right.$ $\left.\mathrm{cm}^{-3}\right)$ and lower resistivity $(0.72 \Omega \mathrm{cm})$ than those for only Mg-doped GaN film.

Besides, from the high resolution x-ray diffraction (HRXRD) measurement as shown in Fig. 5, both (002) and (102) HRXRD full width at half maximum values are broadened by increasing $\mathrm{Cp}_{2} \mathrm{Mg}$ flow rates not DEZn flow rates. So we can conclude that the incorporation of $\mathrm{Zn}$ atoms with $\mathrm{Mg}$ is the technique obtaining high conducting p-type $\mathrm{GaN}$ film without deterioration of the structural qualities of GaN films.

In order to compare Ohmic contact properties for the only Mg-doped $\left(6.0 \times 10^{17}\right.$ $\mathrm{cm}^{-3}$ ) and the $\mathrm{Mg}-\mathrm{Zn}$ co-doped (8.5 X $10^{17} \mathrm{~cm}^{-3}$ ) $\mathrm{p}-\mathrm{GaN}$ films, we performed transmission line method (TLM) with ring contact geometry with outer ring radius of 200 um and gap spacings $(5-45 \mathrm{um})$. The surface of p-type GaN specimens were treated 

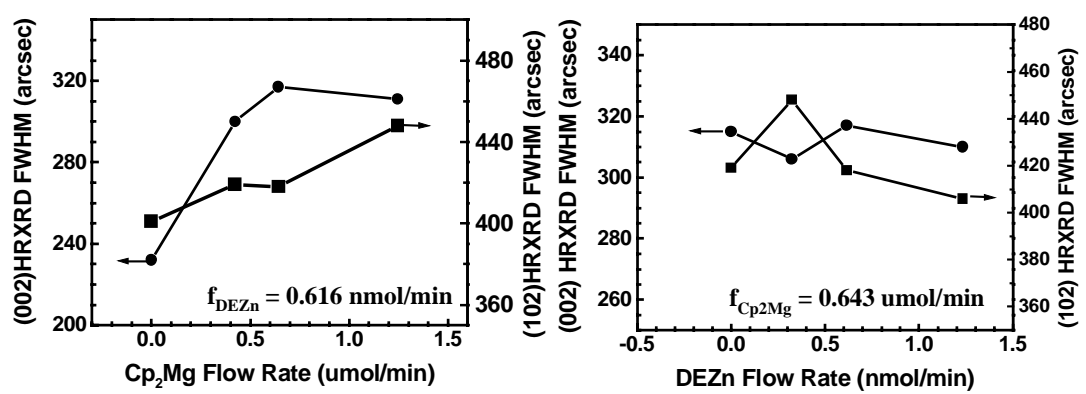

Figure 5, Dependence of (002) and (102) HRXRD FWHMs for the Mg-Zn co-doped GaN films at the condition of (a) various $\mathrm{Cp}_{2} \mathrm{Mg}$ flow rate and constant DEZn flow rate of $0.616 \mathrm{nmol} / \mathrm{min}$, and (b) various DEZn flow rate and a constant $C p_{2} M g$ flow rate of $0.643 \mathrm{umol} / \mathrm{min}$.

using aqua regia[7], followed by the deposition of $\mathrm{Pd}(150 \mathrm{~A}) / \mathrm{Au}(1400 \mathrm{~A})$ Ohmic metals under a vacuum condition of $10^{-5}$ torr. After the metal deposition, the photoresist was lifted off. Current-Voltage (I-V) characteristics of the prepared samples were measured by HP 4155 parameter analyzer.
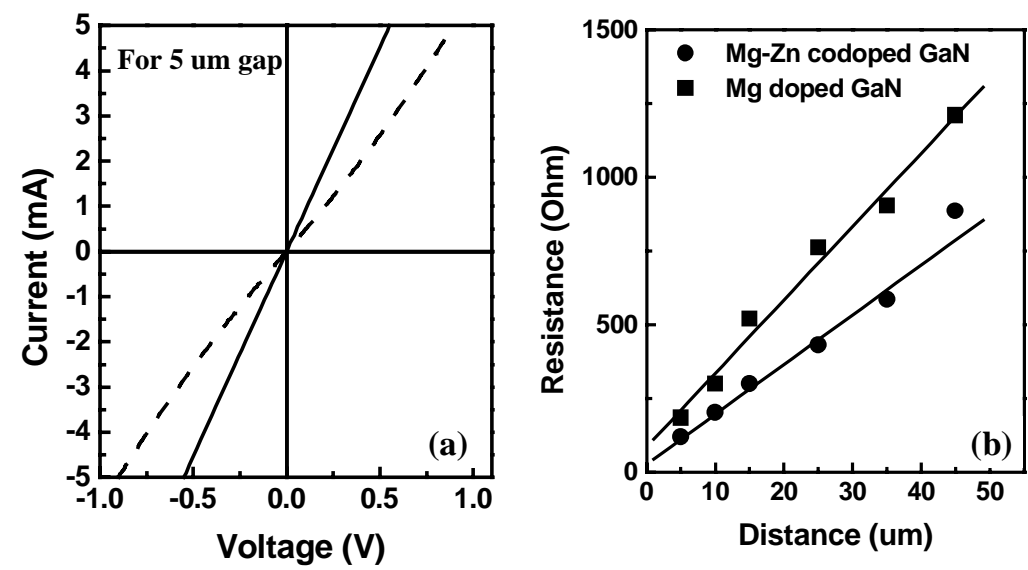

Figure 6, (a) Comparison of the I-V characteristics measured between the contact pads with a gap spacing of $5 \mathrm{um}$. for the only Mg-doped (dashed line) and $\mathrm{Mg}-\mathrm{Zn}$ co-doped p-type GaN films(solid line), (b) Variation of resistance as a function of gap spacing for the only Mg-doped (Solid square) and Mg-Zn co-doped (solid circle) p-type GaN films. solid lines are linear fits of experimental data.

Figure 6 (a) shows the I-V characteristics for both the only Mg-doped and the Mg$\mathrm{Zn}$ co-doped GaN samples, measured between the Ohmic pads with a spacing of $5 \mathrm{um}$. 
The I-V curve obtained is nonlinear for the only Mg-doped sample, but linear for the Mg$\mathrm{Zn}$ co-doped sample over the whole range of voltages. The specific contact resistivities with correction factors [8] taken from the gradients and intercepts in the Fig. 6 (b) are determined [8] to be $1.9 \times 10^{-3} \Omega \mathrm{cm}^{2}$ for the only Mg-doped sample and $5.0 \times 10^{-}$ ${ }^{4} \Omega \mathrm{cm}^{2}$ for the $\mathrm{Mg}-\mathrm{Zn}$ co-doped sample. Note that contact resistivity decreases by one order of magnitude by the co-doping technique. Therefore, the $\mathrm{Mg}-\mathrm{Zn}$ co-doped $\mathrm{GaN}$ layer is expected to act as a good contact layer in device structure.

\section{SUMMARY}

We have found that $\mathrm{Mg}$ doped GaN layer shows high electrical conductivity, when the $[\mathrm{Mg}] /[\mathrm{Ga}]$ ratio in gas phase is $7.6 \times 10^{-3}$. The $\mathrm{Mg}$-Si co-doping characteristics were explained effectively taking advantage of the concept of competitive adsorption between $\mathrm{Mg}$ and $\mathrm{Si}$ during the growth. In other words, the occupation by $\mathrm{Si}$ atom into $\mathrm{Ga}$ sublattice site is easier than that by $\mathrm{Mg}$ atom, since the formation energy of $\mathrm{Si}-\mathrm{N}$ bonding is smaller than that of $\mathrm{Mg}-\mathrm{N}$. We have also grown $\mathrm{p}-\mathrm{GaN}$ film with a resistivity of $1.26 \Omega \mathrm{cm}$ and a hole density of $4.3 \times 10^{17} \mathrm{~cm}^{-3}$ by means of $\mathrm{Mg}-\mathrm{Si}$ codoping technique. For $\mathrm{Mg}-\mathrm{Zn}$ co-doping, $\mathrm{p}-\mathrm{GaN}$ showing low electrical resistivity $(0.7$ $\Omega \mathrm{cm})$ and high hole concentration $\left(8.5 \times 10^{17} \mathrm{~cm}^{-3}\right)$ was successfully grown without the degradation of structural quality of the film. Besides, the specific contact resistance for $\mathrm{Mg}-\mathrm{Zn}$ co-doped GaN film measured by TLM is $5.0 \times 10^{-4} \Omega \mathrm{cm}^{2}$, which is lower value by one order of magnitude than that for only Mg-doped GaN film $\left(1.9 \times 10^{-3} \Omega \mathrm{cm}^{2}\right)$.

\section{REFERENCES}

1. T. Yamamoto and H.K. Yoshida, Jpn. J. Appl. Phys. 36, L180 (1997).

2. O. Brandt, H. Yang, H. Kostial, and K.H. Ploog, Appl. Phys. Lett. 69, 2707 (1996).

3. K.S. Kim, C.S. Oh, K.J. Lee, G.M. Yang, C.-H. Hong, K.Y. Lim, A. Yoshikawa, and H.J. Lee, J. Appl. Phys. 85 (1999) 8441.

4. CRC Handbook of Chemistry and Physics, $55^{\text {th }}$ ed. (CRC, Boca Raton, FL, 1974).

5. U. Kaufmann, M. Kunzer, M. Maier, H. Obloh, A. Ramakrishnan, B. Santic, and P. Schlotter, Appl. Phys. Lett. 72, 1326 (1998).

6. A.K. Viswanath, E.-J. Shin, J.I. Lee, S. Yu, D. Kim, B. Kim, Y. Choi, and C.-H. Hong, J. Appl. Phys. 83, 2272 (1998).

7. J.K. Kim, J.-L. Lee, J.W. Lee, H.E. Shin, Y.J. Park, and T. Kim, Appl. Phys. Lett. 73, 2953 (1998).

8. L.F. Lester, J.M. Brown, J.C. Ramer, L. Zhang, S.D. Hersee, and J.C. Zolper, Appl. Phys. Lett. 69, 2737 (1996).

\section{ACKNOWLEDGEMENTS}

This work has been supported by the KOSEF and the MOST of Korea through the Semiconductor Physics Research Center at Chonbuk National University. 